\title{
Circadian and circannual patterns of stroke
}

\author{
Shereen A. Al-Ahwal', Osama A. Ragab, Ashraf A. Abo Elsafa and Azza A. Ghali
}

\begin{abstract}
Background: Cerebrovascular event peaks occur in the morning $(\approx 9: 00 \mathrm{am})$ with another one peak in the evening $(\approx 8: 00 \mathrm{pm})$ and a trough at night. Knowledge about circadian influences on mechanisms involved in cerebrovascular events is important for optimising the timing of therapy, preventing behavioural triggers at potentially risky circadian phases and selecting the timing of diagnostic procedures. This work aims to evaluate circadian and circannual patterns of stroke onset, and variation in pattern of stroke onset in the month of Ramadan.

Patients and methods: The study was conducted on 98 stroke patients and 98 age- and sex-matched normal subjects. All patients had a documented time of stroke symptom onset. End-tidal carbon dioxide and core body temperature were served as measures of endogenous circadian phase. Cerebral blood flow velocity was measured using transcranial colour-coded duplex. Circadian rhythm of blood pressure and heart rate variability were also assessed.

Results: Both ischaemic and haemorrhagic stroke showed a circadian variation regarding their onset, with the peak in the morning and the nadir during night-time. We found a pathologically reduced or abolished circadian blood pressure variation after stroke.

Conclusion: Stroke was more frequent in the morning; also, it was less likely to occur during the summer and autumn than the winter or spring. Stroke prevention with therapies that target the morning rise in risk factors could be advantageous in reducing the overall risk of stroke.
\end{abstract}

Keywords: Stroke, Circadian pattern, Ramadan

\section{Introduction}

Knowledge of stroke onset periodicity may elucidate the pathophysiological mechanisms of strokes and give a new hope for their prevention [1,2]. Stroke incidence differs not only according to the seasons of the year, but also along the different hours of a day [3]. Stroke patients had rhythmic variation in blood pressure, fibrinolytic system, platelet function, vascular tone, cerebral vasomotor regulation and coagulation factors [4].

Cerebral blood flow velocity (CBFV) varies during 24 $h$ of the day rhythm, suggesting regulation by a circadian oscillator. Despite that, morning reduction of cerebral auto-regulation is not documented [5]. Circadian patterns of blood pressure (BP) changes were reported after stroke, which may have a prognostic and therapeutic implication [6].

Dysfunction of the hypothalamo-pituitary adrenal (HPA) axis was documented in stroke patients [7]. Although many studies have explored the function of this

\footnotetext{
* Correspondence: shereen.neurology@gmail.com

Neurology Department, Tanta University, Tanta 31527, Egypt
}

axis during stroke, the relation between the (HPA) axis and stroke severity remains unclear $[8,9]$.

Fasting during the month of Ramadan is an extreme lifestyle change that may affect stroke patients, as it may last for 11-20 h depending on the geographical location and season [10]. The aim of this study was to evaluate circadian and circannual patterns of stroke onset, and variation in pattern of stroke onset in the month of Ramadan.

\section{Patients and methods}

This observational cross-section study was conducted on three groups, namely group A including 60 patients (35 males, 25 females) with ischaemic stroke, group B including 38 patients (23 males, 15 females) with haemorrhagic stroke and group $\mathrm{C}$ including 98 patients (55 males, 43 females), age- and sex-matched normal subjects and served as control group.

Patients having a history of adrenal insufficiency or receiving drugs known to affect the HPA axis such as rifampicin, antifungal agents, $\beta$-blockers or anticonvulsants [11] were excluded. Also, patients suffering heart failure, cardiomyopathy, chronic obstructive pulmonary disease, 
renal dysfunction or severe obesity were excluded as they affect blood pressure circadian rhythm [12].

The $24 \mathrm{~h}$ of the day were divided into four quartiles: first quartile from 12:01 am to 6:00 am, second quartile from 6:01 am to $12: 00 \mathrm{pm}$, third quartile from 12:01 pm to $6: 00 \mathrm{pm}$ and fourth quartile from $6: 01 \mathrm{pm}$ to $12: 00$ am. The study was carried out over 1 year and included the Muslims' holy month of Ramadan; patients presented with stroke during that month were compared to patients presented during the rest of the year, to investigate the relation between fasting and circadian pattern of stroke onset.

On admission, all stroke patients were submitted to history taking, general medical examination and neurological evaluation by National Institute of Health Stroke Scale (NIHSS) and Modified Rankin Scale (mRS). On different quartiles of the day starting after admission, CBFV of the middle cerebral artery (MCA) was measured using transcranial colour-coded duplex (TCCD) (Ultrasound Philips HD $11^{\mathrm{Tm}}$, USA; phased array transducer of multi-frequency [1-3] $\mathrm{MHz}$, through temporal window) to detect fluctuations along the time of day. End-tidal carbon dioxide (EtCO2) and core body temperature (CBT) were recorded during the four quartiles.

The mean daytime and night-time BP was calculated, and the values were analysed to detect the diurnal variation and whether there is nocturnal fall of BP or not. According to the percentage fall in the mean BP at night compared with that during the day, patients were classified as dippers (fall 10-20\%), extreme dippers (>20\%), non-dippers $(<10 \%)$ or reverse dippers (the mean nocturnal BP exceeded the mean daytime BP) [13].

The autonomic balance was assessed with evaluating its relationship with stroke through measurement of heart rate variability (HRV), which has been derived from the recording of ECG Holter monitoring (VX3+ Digital Holter Recorder, Intricon ${ }^{\mathrm{Tx}}$, USA). The mean values of the night hours (first quartile), the day hours (second and third quartiles) and the night to day ratios of the different measures of HRV were calculated. Blood cortisol level was assessed in the first and second quartiles. Plasma fibrinogen was measured to assess blood viscosity during the first and second quartiles.

Group $C$ personnel were subjected to evaluation of their circadian pattern through measurement of blood pressure, plasma fibrinogen, cerebral blood flow velocity, $\mathrm{EtCO} 2$ and blood level of cortisol at the same time of the patient group. All stroke patients were followed up after 3 months later by assessment of NIHSS and mRS to evaluate the functional outcome and cardiac autonomic dysfunction after stroke. An informed signed consent was obtained from all participants or their first-degree relative and a consent for publication was obtained also, and the study protocol was approved by the Faculty of Medicine, Tanta University Research Ethical Committee under number 1109/04/12.

\section{Statistical analysis}

The collected data were organised, tabulated and statistically analysed using SPSS software statistical computer package version 16. For quantitative data, the range in addition to mean and standard deviation were calculated. For qualitative data, comparison between two groups and more was done using chi-square test $\left(\chi^{2}\right)$. Significance was adopted at $p<0.05$ for interpretation of results of tests of significance. ANOVA test was used for comparison among different times in the same group in quantitative data.

\section{Results}

The study included three groups: group A (ischaemic stroke patients), group B (haemorrhagic stroke patients) and group $\mathrm{C}$ (control). The groups were sex and age matched. There was a statistically significant trend towards an increased risk of stroke in the morning hours with a peak of onset between $6 \mathrm{am}$ and $12 \mathrm{pm}$ (second quartile). Thirty-six patients of all studied patients had stroke at morning hours while the least number was at night-time (12 am-6 am) (first quartile) ( $P$ value, $0.004 *)$ (Table 1).

There was significant difference regarding gender and age variations, as patients with night onset stroke were more frequently women $62.5 \%$ and older than other patients ( $P$ value, 0.002$)$. Also, $50 \%$ of night stroke patients (first quartile) had severe disability when evaluated by NIHSS and mRS.

There was a statistically significant increase of stroke incidence in the winter months (December to March) 41 patients $(41.8 \%)$ followed by spring months 21 patients (21.4\%) (March to June) ( $P$ value, 0.001$)$ (Table 2$)$.

Table 1 Circadian variation of stroke onset

\begin{tabular}{|c|c|c|c|c|c|c|c|}
\hline \multirow{2}{*}{\multicolumn{2}{|c|}{$\begin{array}{l}\text { Total } \\
\text { number }\end{array}$}} & \multirow{3}{*}{$\begin{array}{l}\text { 1st quartile } \\
\text { (12.01 am-6.00 am) } \\
\text { (16) }\end{array}$} & \multirow{3}{*}{$\begin{array}{l}\text { 2nd quartile } \\
\text { (6.01 am-12.00 noon) } \\
\text { (36) }\end{array}$} & \multirow{3}{*}{$\begin{array}{l}\text { 3rdquartile } \\
\text { (12.01 pm-6.00 pm) } \\
(27)\end{array}$} & \multirow{3}{*}{$\begin{array}{l}\text { 4th quartile } \\
\text { (6.01 pm-12 midnight) } \\
\text { (19) }\end{array}$} & \multicolumn{2}{|c|}{ Chi-square } \\
\hline & & & & & & \multirow{2}{*}{$\frac{x^{2}}{13.116}$} & \multirow{2}{*}{$\begin{array}{c}\text { P value } \\
0.004^{*}\end{array}$} \\
\hline$N$ & 98 & & & & & & \\
\hline$\%$ & 100 & 16.3 & 36.7 & 27.5 & 19.3 & & \\
\hline
\end{tabular}

*Significant 
Table 2 Circannual variation of stroke onset

\begin{tabular}{lcccccc}
\hline $\begin{array}{l}\text { Total } \\
\text { number }\end{array}$ & Spring & Summer & Autumn & Winter & \multicolumn{2}{c}{ Chi-square } \\
\hline$N(98)$ & 21 & 18 & 18 & 41 & 20.082 & $<0.001^{*}$ \\
$\%(100)$ & 21.4 & 18.36 & 18.36 & 41.8 & & \\
\hline
\end{tabular}

*Significant

During the month of Ramadan (MOR), the stroke onset time was mainly in the third quartile (12.01 pm-6 pm) $50 \%$. While in other months (OM), the higher frequency of stroke onset time was mainly in the second quartile (6.01 am-12 noon) $58.3 \% \quad(P$ value, 0.035$)$ (Fig. 1).

Group C (normal subjects) showed significant difference between day and night time regarding $\mathrm{BP}$ variability, while in patients' groups, there was loss of normal nocturnal dipping of BP in 59 patients (Fig. 2). This non-dipping pattern was seen in both stroke patients' groups. Out of 59 non-dippers, 16 patients were extreme dippers and 12 patients were reverse dippers.

Group C (normal subjects) showed significant difference in HRV between day and night time values, as night values were higher than day, while patients' groups showed loss of these differences.

In group $C$ (normal subjects), cerebral blood flow velocity had circadian periodicity between morning and evening. This circadian periodicity reached a significant difference, as it was lower in the morning (second quartile) than in the evening (fourth quartile), while group A patients (ischaemic stroke) showed significantly lower levels of CBF velocity with no significant difference between both quartiles ( $P$ value, 0.001$)$ (Table 3$)$.
Patients in group B (haemorrhagic stroke) and group C (normal subjects) showed circadian variation in plasma fibrinogen, which was lost in ischaemic stroke patients (Table 4). Also in group $\mathrm{C}$, there was circadian variation in plasma cortisol level, which was lost in both patient groups (Table 5).

Patients with sleep stroke onset (first quartile) had worst prognosis during the follow-up, about $62 \%$ of patients presented with sleep stroke had worse prognosis either dead $(37 \%)$ or had severe degree of disability (25\%) (Fig. 3).

Regarding BP changes, patients' extreme and reverse dipping had worst prognosis. About $66 \%$ of patients presented with reverse dipper pattern, and $62 \%$ of patients with extreme dipper pattern had worse prognosis either dead $(41 \%)(25 \%)$ or had severe degree of disability (25\%) (37\%), respectively (Fig. 4).

\section{Discussion}

The suprachiasmatic nucleus $(\mathrm{SCN})$ mediates the circadian rhythms [14], which control a variety of biological processes, such as sleep-wake cycle, core body temperature, glucose homeostasis hormone secretion and cell-cycle regulation. The disturbance of circadian rhythms can result in internal desynchronization [15].

The present study showed that there were both circadian and seasonal patterns of stroke onset and indicated that such temporal variability was influenced by different combinations of cardiovascular risk factors. Most studies Casetta et al. [16], Kario et al. [17] and Butt et al. [18] confirmed our findings and documented the peak of stroke onset between 6:01 am and 12:00 pm. On the other hand, Nahrir et al. [19] found that most strokes occur from $12.01 \mathrm{am}$ to $6 \mathrm{am}$. We also did not agree with

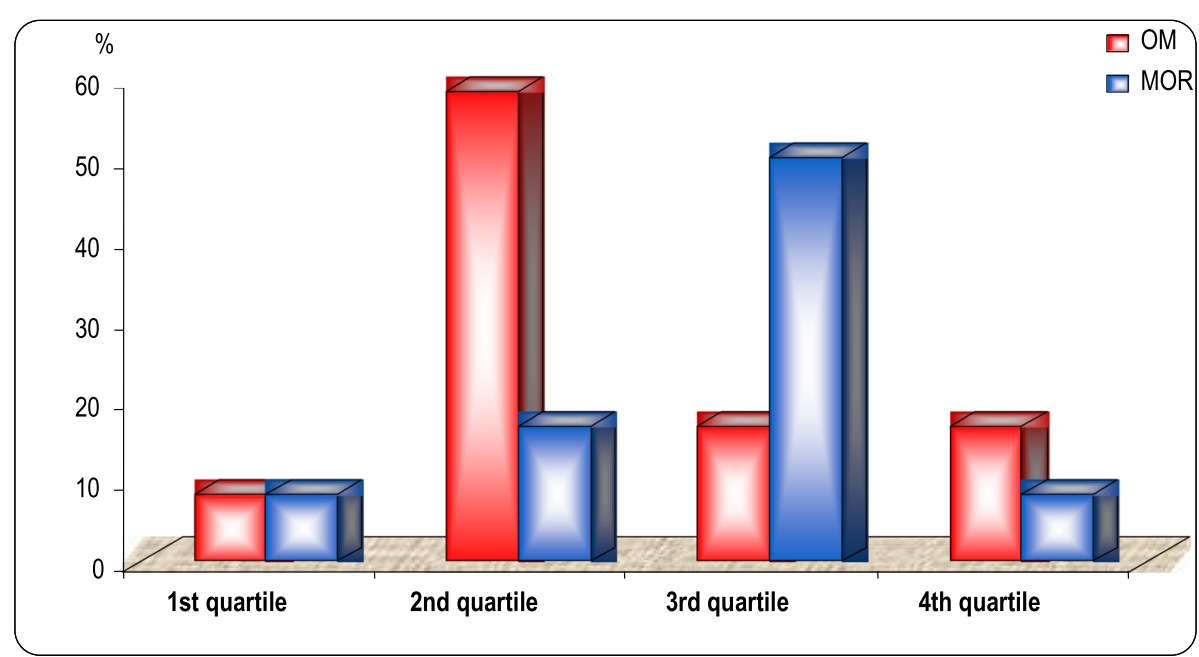

Fig. 1 Circadian variation of stroke onset 1 month before and during the month of Ramadan 


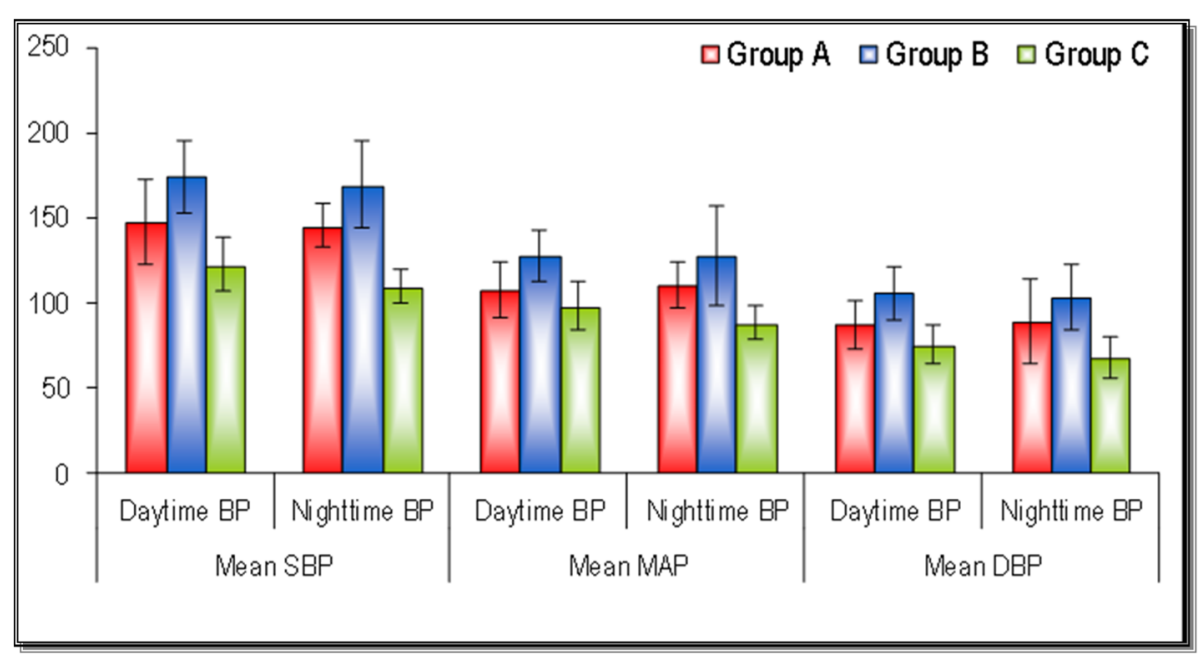

Fig. 2 Difference in $24 \mathrm{~h}$ mean blood pressure measurement between patients and control groups

Kallet [20] in their finding that there was no difference in circadian variation regarding the aetiologic distribution or in the clinical stroke subtypes. The methodology of the previous studies had not been uniformed, as some investigators chose to divide the clock into quartiles, as we did, while others narrowed the time epochs further into 2-h subunits.

Fasting (no food or fluid intake) during the holy Ramadan month is mandatory for all healthy adult Muslims from dawn to sunset for a period of one lunar month. Changes in lifestyle during Ramadan month affect the circadian rhythm and influence the timing of presentation of cerebral stroke [21].

In patients presented with stroke during Ramadan month, there was a significant shift with the higher frequency of stroke onset time which was mainly in the third quartile $(12.01 \mathrm{pm}-6 \mathrm{pm})$. This was in concordance with the previous studies Anderson et al. [22] Manfredini et al. [2] and El Mitwalli et al. [10]. During Ramadan, the changes in food intake and sleep timing and then shift of cortisol profile affect the circadian rhythm and influence the timing of presentation of cerebral stroke.

Table 3 Mean cerebral blood flow velocity level in stroke patients and control group

\begin{tabular}{|c|c|c|c|c|c|}
\hline & \multicolumn{3}{|c|}{ Mean cerebral blood flow velocity $(\mathrm{cm} / \mathrm{s})$} & \multicolumn{2}{|l|}{ ANOVA } \\
\hline & Group A (60) & Group B (38) & Group C (98) & $\bar{f}$ & $P$ value \\
\hline 2nd quartile & $39.8 \pm 2.5$ & $39.5 \pm 3.1$ & $45.6 \pm 1.7$ & 186.040 & $<0.001^{*}$ \\
\hline 4th quartile & $41.1 \pm 6.9$ & $48.5 \pm 4.3$ & $50.7 \pm 5.6$ & 17.510 & $<0.001^{*}$ \\
\hline$T$ test $t$ & 1.372 & 10.466 & 8.627 & & \\
\hline$P$ value & 0.172 & $<0.001^{*}$ & $<0.001^{*}$ & & \\
\hline
\end{tabular}

*Significant
Variety of abnormal diurnal variation patterns had been found among our patients. There was loss of normal nocturnal dipping of BP in 59 patients. Our finding was in accordance with Chrousos [7], who found that the normal diurnal variation in $\mathrm{BP}$ was abolished in stroke patients and this non-dipping was equally seen in both ischaemic and haemorrhagic groups. Diminished nocturnal blood pressure decline could be explained by disturbance of the central autonomic nervous system with nocturnal reduction of sympathetic activity and increased parasympathetic activity. Excess secretion of cortisol and epinephrine in the acute phase of stroke attenuates the fall of blood pressure.

The results of this study revealed the abolition of the circadian rhythm of HRV and a loss of the relative vagal nocturnal dominance in patients with acute stroke. Our results agreed with the previous findings of reduced HRV after both types of stroke. Barron et al. [23] and Naver et al. [24] found that both ischaemic and haemorrhagic lesions located either hemispheric or in the brainstem may result in impaired HRV. The circadian variation in HRV seems more likely to be a result of

Table 4 Mean plasma fibrinogen level in stroke patients and control group

\begin{tabular}{lllllll}
\hline & \multicolumn{2}{l}{ Mean plasma fibrinogen level $(\mathrm{g} / \mathrm{l})$} & & \multicolumn{2}{l}{ ANOVA } & \\
\cline { 2 - 3 } & Group A & Group B & Group C & & & $P$ value \\
\hline 1st quartile & $3.9 \pm 0.41$ & $3.4 \pm 0.2$ & $3.1 \pm 0.2$ & & 115.407 & $<0.001^{*}$ \\
2nd quartile & $4.1 \pm 0.7$ & $3.5 \pm 0.2$ & $3.6 \pm 0.3$ & & 382.400 & $<0.001^{*}$ \\
$T$ test $t$ & 1.910 & 2.739 & 13.728 & & \\
\multicolumn{1}{c}{$P$ value } & 0.068 & $0.007^{*}$ & $<0.001^{*}$ & & \\
\hline
\end{tabular}

*Significant 
Table 5 Mean plasma cortisol level in stroke patients and control group

\begin{tabular}{|c|c|c|c|c|c|}
\hline & \multicolumn{3}{|c|}{ Mean plasma cortisol level ( $\mu \mathrm{g} / \mathrm{dl})$} & \multicolumn{2}{|l|}{ ANOVA } \\
\hline & Group A (60) & Group B (38) & Group C (98) & $\bar{f}$ & $P$ value \\
\hline 1st quartile & $24.6 \pm 10.2$ & $23.7 \pm 10.4$ & $10.3 \pm 5.2$ & 72.249 & $<0.001^{*}$ \\
\hline 2nd quartile & $27.6 \pm 14.6$ & $27.3 \pm 13.5$ & $19.7 \pm 6.9$ & 11.976 & $<0.001^{*}$ \\
\hline$T$ test $t$ & 1.305 & 1.302 & 6.707 & & \\
\hline$P$ value & 0.195 & 0.196 & $<0.001^{*}$ & & \\
\hline
\end{tabular}

*Significant

sympathetic inhibition rather than a parasympathetic effect as the presence of vagal neuropathy did not affect it.

The low CBFV in the morning is thought to be a consequence of the fall in the overall reduced metabolic level and reduced cognitive processing. Additionally, recumbent sleeping position with reduction of physical activity contributes to the decline in CBFV [5]. The results of this study revealed that in normal subjects, there was circadian periodicity in CBFV with significant difference; it was lower in the morning (second quartile) than in the evening (fourth quartile).

In comparison between different groups, we found that group A showed significantly lower levels of CBF velocity. Our findings were in accordance with Novak et al. [25], who found that BFVs were lower by approximately $30 \%$ in the patients with ischaemic stroke compared with the control subjects. These findings also agreed with Salinet et al. [26], who found that recordings revealed a significantly lower $\mathrm{CBFV}$ in the affected hemisphere within $72 \mathrm{~h}$ after stroke compared to controls.

Follow-up of patients after 3 months revealed that HRV values returned to normal. These results agreed with findings of Binici et al. [27], who reported that the abolition of the circadian rhythm of HRV and a loss of the relative vagal nocturnal dominance in patients with acute stroke seemed to be reversible.

In stroke patients, the plasma cortisol level returned to normal values with reappearance of normal circadian rhythm. Butt et al. [18] found that cerebral stroke induced abnormalities of cortisol circadian secretion while in convalescent period, these cortisol abnormalities were transient.

Follow-up of clinical severity according to stroke onset by NIHSS is as follows: our results showed that sleep stroke (first quartile) had worst prognosis and worse functional outcome after 3 months (measured by mRS). Our study has been in accordance with Jiménez-Conde et al. [28], who found that sleep stroke had high severity and worse prognosis.

Follow-up of clinical severity according to BP changes by NIHSS is as follows: the reverse dippers and extreme dippers had worse functional outcome after 3 months (measured by mRS). This agreed with Kario et al. [29], who found that the fatal stroke incidence was significantly higher in reverse dippers. These results suggest that nocturnal extreme dippers are more liable to ischaemic strokes due to the associated cerebral hypoperfusion during the night.

\section{Conclusion}

The results of this study confirm the existence of both circadian and seasonal patterns of onset of stroke. The normal diurnal blood pressure variation was abolished in all stroke patients. Acute stroke results in loss of the relative vagal nocturnal dominance, which may precipitate cardiac arrhythmias and other cardiovascular

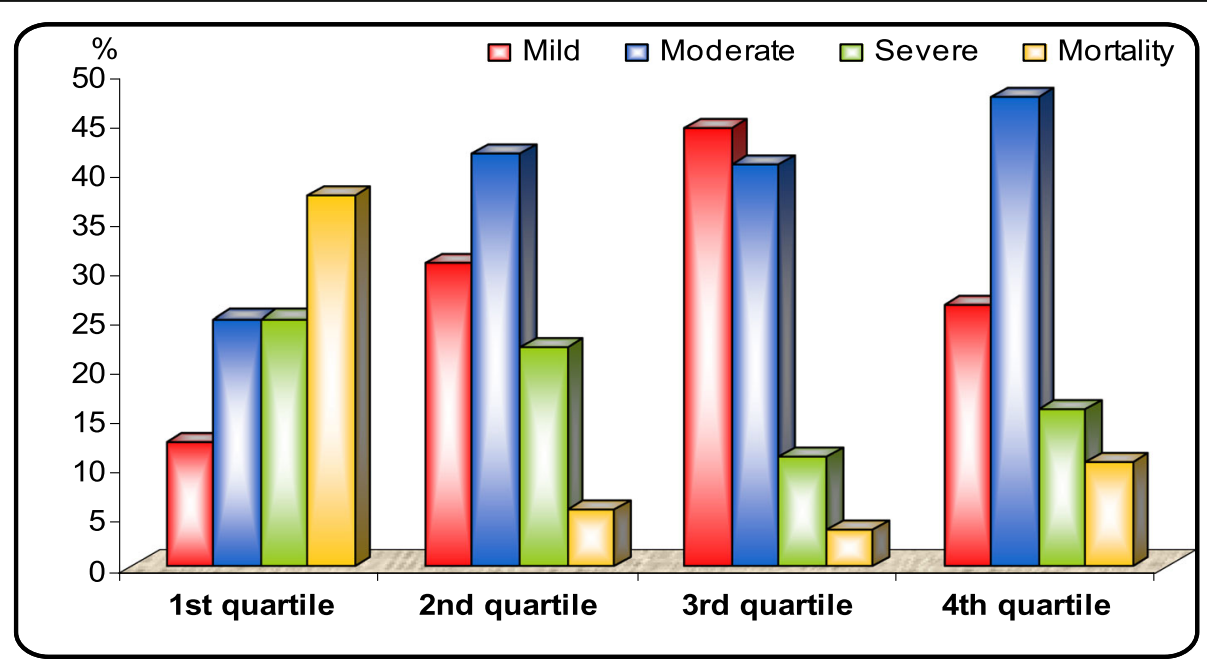

Fig. 3 Follow-up clinical severity according to stroke onset by NIHSS after 3 months 


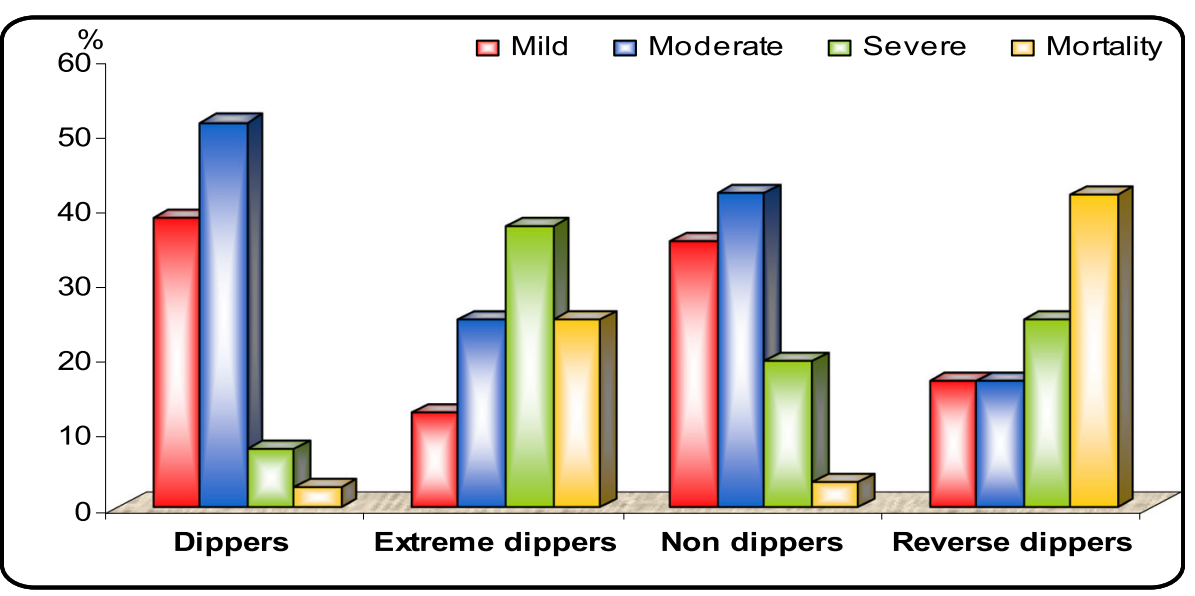

Fig. 4 Follow-up clinical severity according to blood pressure changes after 3 months

complications. Circadian fluctuation of heart rate variability is reversibly abolished in the acute phase of stroke and resumed during the subsequent 3 months. During the month of Ramadan, there is a significant shift with the higher frequency of stroke onset time which is mainly in the afternoon hours (12 pm-6 pm).

\section{Abbreviations}

BP: Blood pressure; CBF: Cerebral blood flow; CBFV: Cerebral blood flow velocity; CBT: Core body temperature; DR: During Ramadan; EtCO2: End-tidal carbon dioxide; HPA: Hypothalamo-pituitary adrenal; HRV: Heart rate variability; MCA: Middle cerebral artery; MOR: The month of Ramadan; mRS: Modified Rankin Scale; NIHSS: National Institute of Health Stroke Scale; OM: Other months; TCCD: Transcranial colour-coded duplex

\section{Acknowledgements}

We wish to express our great appreciation to our patients and their family for supporting us during this work, also we should express our deep thanks for Professor Mohamed Osman and Professor Yosri Elsenosy for their guidance during this work. Finally, we should thank Ms. Hagar Aboelfath Belal for her help in editing this manuscript.

\section{Funding}

This research did not receive any specific grant from funding agencies in the public, commercial, or not-for-profit sectors.

\section{Availability of data and materials}

All raw data will be available on the editor request.

\section{Authors' contributions}

All authors have participated in designing the study, acquisition of data, data interpretation and revising. SA recruited the patient and carried out the clinical, neurological evaluation, cerebral blood flow evaluation by TCCD and editing the manuscript. OR participated in the cerebral blood flow evaluation by TCCD, interpretation of the study results and revision of manuscript. AA recruited some patient and carried out clinical, neurological evaluation and participated in the interpretation of the study results. AG recruited some patient and carried out clinical, neurological evaluation and participated in interpretation of the study results. All authors read and approved the final manuscript.

\section{Ethics approval and consent to participate}

The study protocol was approved by The Research Ethics Committee and Quality Assurance Unit, Faculty of Medicine, Tanta University under the code number (1109/04/12) on April 2012. Participation was voluntary and all contributors or their first-degree relatives received detailed information about the aims of this research work and an informed consent was obtained prior to the commencement of the study.
Consent for publication

A written informed consent for the publication was obtained from all the participants (or their first degree relatives).

\section{Competing interests}

The authors declare that they have no competing interests.

\section{Publisher's Note}

Springer Nature remains neutral with regard to jurisdictional claims in published maps and institutional affiliations.

Received: 25 October 2017 Accepted: 3 January 2019

Published online: 15 January 2019

References

1. Caro JJ, Huybrechts KF, Duchesne I. Management patterns and costs of acute ischemic stroke. Stroke. 2000;31(3):582-90.

2. Manfredini R, Boari B, Smolensky MH, Salmi R, la Cecilia O, Maria Malagoni A. Haus E, Manfredini F. Circadian variation in stroke onset: identical temporal pattern in ischemic and hemorrhagic events. Chronobiol Int. 2005; 22(3):417-53.

3. Wang Y, Levi CR, Attia JR, D'Este CA, Spratt N, Fisher J. Seasonal variation in stroke in the Hunter Region, Australia. Stroke. 2003;34(5):1144-50.

4. Tischkau SA, Cohen JA, Stark JT, Gross DR, Bottum KM. Time-of-day affects expression of hippocampal markers for ischemic damage induced by global ischemia. Exp Neurol. 2007;208(2):314-22.

5. Diamant M, Harms MP, Immink RV, Van Lieshout JJ, Van Montfrans GA. Twenty-four-hour non-invasive monitoring of systemic haemodynamics and cerebral blood flow velocity in healthy humans. ActaPhysiologica. 2002; 175(1):1-9.

6. Jain S, Namboodri KK, Kumari S, Prabhakar S. Loss of circadian rhythm of blood pressure following acute stroke. BMC Neurol. 2004:4(1):1.

7. Chrousos GP. Stress and disorders of the stress system. Nat Rev Endocrinol. 2009:5(7):374-81.

8. Dimopoulou I, Tsagarakis S. Hypothalamic-pituitary dysfunction in critically ill patients with traumatic and nontraumatic brain injury. Intensive Care Med. 2005;31(8):1020-8.

9. Widmer IE, Puder JJ, König C, Pargger H, Zerkowski HR, Girard J, Müller B. Cortisol response in relation to the severity of stress and illness. J Clin Endocrinol Metab. 2005;90(8):4579-86.

10. El-Mitwalli A, Zaher AA, El Menshawi E. Circadian rhythm of stroke onset during the month of Ramadan. Acta Neurol Scand. 2010;122(2):97-101.

11. Bornstein SR. Predisposing factors for adrenal insufficiency. N Engl J Med. 2009;360(22):2328-39.

12. Rahman A, Hasan AU, Nishiyama A, Kobori H. Altered circadian timing system-mediated non-dipping pattern of blood pressure and associated cardiovascular disorders in metabolic and kidney diseases. Int J Mol Sci. 2018;19(2):400. 
13. Pickering TG. The clinical significance of diurnal blood pressure variations. Dippers and nondippers. Circulation. 1990;81(2):700-2.

14. Golombek DA, Rosenstein RE. Physiology of circadian entrainment. Physiol Rev. 2010;90(3):1063-102

15. Zee PC, Attarian H, Videnovic A. Circadian rhythm abnormalities. Continuum (Minneap Minn). 2013;19(1 Sleep Disorders):132.

16. Casetta I, Granieri E, Fallica E, la Cecilia O, Paolino E, Manfredini R. Patient demographic and clinical features and circadian variation in onset of ischemic stroke. Arch Neurol. 2002;59(1):48-53.

17. Kario K, Pickering TG, Umeda $Y$, Hoshide S, Hoshide $Y$, Morinari M, Murata M, Kuroda T, Schwartz JE, Shimada K. Morning surge in blood pressure as a predictor of silent and clinical cerebrovascular disease in elderly hypertensives. Circulation. 2003:107(10):1401-6.

18. Butt MU, Zakaria M, Hussain HM. Circadian pattern of onset of ischaemic and haemorrhagic strokes, and their relation to sleep/wake cycle. J Pak Med Assoc. 2009;59(3):129-32.

19. Nahrir S, Khan A, Alsenani F. Uncommon stroke disorders characteristics of wake-up stroke through the timing - an experience from an Arab cohort. Int J Stroke. 2014;9:315-6.

20. Kallet RH. Capnography and respiratory care in the 21st century. Respir Care. 2008:53(7):860.

21. Akhan G, Kutluhan S, Koyuncuoglu HR. Is there any change of stroke incidence during Ramadan? Acta Neurol Scand. 2000;101(4):259-61.

22. Anderson N, Feigin V, Bennett D, Broad J, Pledger M, Anderson C, Diurnal BR. Weekly, and seasonal variations in stroke occurrence in a populationbased study in Auckland, New Zealand. N Z Med J. 2004;117(1202):U1078.

23. Barron SA, Rogovski ZE, Hemli J. Autonomic consequences of cerebral hemisphere infarction. Stroke. 1994;25(1):113-6.

24. Naver HK, Blomstrand C, Wallin BG. Reduced heart rate variability after rightsided stroke. Stroke. 1996;27(2):247-51.

25. Novak V, Hu K, Desrochers L, Novak P, Caplan L, Lipsitz L, Selim M. Cerebral flow velocities during daily activities depend on blood pressure in patients with chronic ischemic infarctions. Stroke. 2010:41(1):61-6.

26. Salinet AS, Panerai RB, Robinson TG. The longitudinal evolution of cerebral blood flow regulation after acute ischaemic stroke. Cerebrovasc Dis Extra. 2014;4(2):186-97.

27. Binici Z, Mouridsen MR, Køber L, Sajadieh A. Decreased nighttime heart rate variability is associated with increased stroke risk. Stroke. 2011;42(11):3196-201.

28. Jiménez-Conde J, Ois A, Rodríguez-Campello A, Gomis M, Roquer J. Does sleep protect against ischemic stroke? Less frequent ischemic strokes but more severe ones. J Neurol. 2007;254(6):782-8.

29. Kario K, Pickering TG, Matsuo T, Hoshide S, Schwartz JE, Shimada K. Stroke prognosis and abnormal nocturnal blood pressure falls in older hypertensives. Hypertension. 2001;38(4):852-7.

\section{Submit your manuscript to a SpringerOpen ${ }^{\circ}$ journal and benefit from:}

- Convenient online submission

- Rigorous peer review

- Open access: articles freely available online

- High visibility within the field

- Retaining the copyright to your article

Submit your next manuscript at $\boldsymbol{\nabla}$ springeropen.com 